\title{
Real-time Efficiency Analysis and System Efficiency Evaluation of Grid-connected PV Power Station Based on Mechanism Model
}

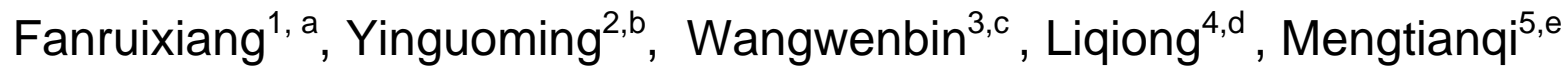 \\ $1,2,3,4,5$ State Power Research Institute of Jiangxi electric power company, Beijing,100094 China \\ a,b,c,d,e Iuow@enacs.com.cn
}

Keywords: PV power station; real-time efficiency; mechanism model Abstract.

Presently, the real-time efficiency analysis of grid-connected PV station still lacks in real algorithm and study. To solve this, firstly, it is necessary to put forward the computational data needed in efficiency analysis according to classical celestial coordinate system; secondly, it is necessary to get the theoretical generated energy of PV module with fixed inclination according to solar irradiation principle and to calculate the real-time efficiency of the PV station according to the geographic longitude of certain station and the module's real-time working temperature after revision; lastly, it is necessary to put forward deficiency in design and measures to elevate the generating efficiency of power station according to the real operating situation of the power station.

\section{Introduction}

During recent years, numerous large MW-level grid-connected PV power stations connect to grid and put into production in succession. Different PV stations distribute in different areas with different climate conditions; moreover, differences exist in PV module, inverter, main electrical wiring, and high voltage apparatus. Under real running status, it lacks in uniform assessment criteria in the advantages and disadvantages in design, construction and operation. This paper starts from the mechanism of electricity generation of PV power station and analyzes the computing method of the real-time efficiency of PV power station. This method in this paper can avoid this problems and only such data as geographical location, PV module inclination, real-time irradiation data, generating capacity of inverter outlet, generating capacity of power station, working temperature of PV module, and so on.

\section{Algorithm of moving trajectory of the sun}

In celestial geometry, the position of the sun gets across following spherical surface. The declination of the sun $\delta$ can be got according to the following formula:

$$
\delta=23.45 \sin [\pi / 2(\alpha 1 / \mathrm{N} 1+\alpha 2 / \mathrm{N} 2+\alpha 3 / \mathrm{N} 3+\alpha 4 / \mathrm{N} 4)]
$$

In the formula, $\mathrm{N} 1$ is 92.975 (number of days from vernal equinox day to summer solstice); $\mathrm{N} 2$ is 93.629 (number of days from summer solstice to autumn equinox); $\alpha 2$ is the number of days from summer solstice; N3 is 89.865 (number of days from autumn equinox to winter solstice); $\alpha 3$ is the number of days from autumn equinox; N4 is 89.012 (number of days from winter solstice to vernal equinox day); $\alpha 4$ is the number of days from winter solstice. The solar altitude a:

$$
\sin \alpha=\sin \varphi \sin \delta+\cos \varphi \cos \delta \cos \omega
$$

In the formula: $\varphi$ is geographic latitude; $\delta$ is declination of the sun; $\omega$ is solar hour angle. Solar hour angle $\omega$ is:

$$
\omega=15(12-\mathrm{Th}-\mathrm{Tm} / 60)
$$

In the formula: $\mathrm{T}_{\mathrm{h}}$ is hour (apparent solar time); Tm is minute (apparent solar time). Solar azimuth $\gamma:$ 
$\cos \gamma=(\sin \alpha \times \sin \varphi-\sin \delta) / \cos \alpha \cos \varphi$

According to formula (4), at the moment of the sun appearing on the horizon line, the solar altitude is zero; the hour angles of sunrise and sunset can be calculated and the sunshine duration of a day can be got.

Solar radiation principle

According to the solar radiation principle, the solar radiation received horizontally include direct radiation and scattered radiation. Therefore,

$$
\mathrm{Qp}=\mathrm{Sp}+\mathrm{Dp}
$$

In the formula: Qp refers to the global radiation received horizontally; Sp refers to the direct radiation received horizontally; Dp refers to the scattered radiation received horizontally.

To elevate the generating capacity, in solar power stations, battery panels face towards the equator with certain angle. To ensure the solar radiation on the tilted surface, the method put forward by Klein is usually taken to calculate:

$$
\mathrm{Qt}=\mathrm{St}+\mathrm{Dt}+\mathrm{Rt}
$$

In the formula, Qt refers to the global radiation received from the inclined plane; St is the direct radiation received from the inclined plane; $\mathrm{Dt}$ is the scattered radiation received by the inclined plane; Rt refers to the ground return received from the inclined plane. Therefore,

$$
\begin{aligned}
& \mathrm{St}=\mathrm{Sp} \cos \theta \\
& \mathrm{Dt}=\mathrm{Dp}(1+\cos \beta) / 2 \\
& \mathrm{Rt}=\rho \mathrm{Qp}(1-\cos \beta) / 2
\end{aligned}
$$

In the formula (9), $\rho$ is the surface albedo; the surface albedos of various kinds of objects on the earth can refer to Table 1; the PV stations in this paper takes $25 \%$.

Table 1 Reflectivity of different ground surfaces

\begin{tabular}{|c|c|c|c|}
\hline State of ground & Reflectivity $/ \%$ & State of ground & Reflectivity /\% \\
\hline Dry ground & 14 & Forest & $4 \sim 10$ \\
\hline Moist black soil & 8 & Dry sandy ground & 18 \\
\hline Dry gray ground & $25 \sim 30$ & Moist sandy ground & 9 \\
\hline Moist gray ground & $10 \sim 12$ & New snow & 81 \\
\hline Dry grassland & $15 \sim 25$ & Unmelted snow & $46 \sim 70$ \\
\hline Moist grassland & $14 \sim 26$ & - & - \\
\hline
\end{tabular}

In the horizontal coordinate system, the general formula of the incident angle of the sun on the inclined plane $\cos \theta$ is:

$\cos \theta=\sin \alpha \cos \beta+\cos \alpha \sin \beta \cos (\gamma-\gamma 5)(10)$

In the formula: $\theta$ is e incident angle of the sun; $\beta$ is the obliquity of inclined plane; $\gamma 5$ is the azimuth angle of inclined plane. The solar panel fixed towards the south has the angle $\gamma 5=0$. The incident angle of the sun on the inclined plane $\cos \theta \operatorname{can}$ be gained according to the calculation of the local latitude, and hour. In the operation, the power station collect the total solar radiation of the horizontal plane, and it is necessary to divide the total solar radiation into direct radiation and scattered radiation before getting the theoretical generating capacity of the inclined PV modules according to formula (7) $\sim(9)$. According to the ratio of the hour scattered radiation quantity and total radiation, which is put forward by Erbs et al., the direct radiation can be gained after division: 


$$
\begin{aligned}
& \mathrm{Dp} / \mathrm{Qp}=0.9511-0.1607 \mathrm{k}_{\mathrm{t}}+4.388 \mathrm{k}_{\mathrm{t}}{ }^{2}+16.638 \mathrm{k}_{\mathrm{t}}{ }^{3}+12.336 \mathrm{kt}^{4}, 0.22<\mathrm{kt} \leqslant 0.8 \\
& \mathrm{Dp} / \mathrm{Qp}=0.165, \quad \mathrm{kt}>0.80
\end{aligned}
$$

In the formula: $\mathrm{kt}=\mathrm{Dp} / \mathrm{Q} 0, \mathrm{Q} 0$ is solar constant, with the reference value of $1367 \mathrm{~W} / \mathrm{m} 2$.

\section{Real-time generating efficiency calculation}

The time of various regions in China uses Beijing time; in the calculation above, all the moments adopt solar time. The following formula can be taken to convert Beijing time into local solar time.

$$
\mathrm{T}_{\text {solar }}=\mathrm{T}_{\mathrm{st}}+4(120-\varphi+\mathrm{e}
$$

In the formula: $\mathrm{T}_{\text {solar }}$ is local real solar time; $\mathrm{T}_{\mathrm{s}}$ is Beijing time; $\varphi$ is geographic longtitude; $\mathrm{e}$ is time difference.

Meanwhile, at the time of calculating the real-time generating capacity of PV modules; the following formula can taken to correct real generating capacity according to the working temperature of battery panel.

$$
\mathrm{G}_{\mathrm{R}}=\mathrm{G}_{\mathrm{T}}\left(1-\left(\mathrm{T}_{\mathrm{R}}-25\right) \mathrm{CO}_{\mathrm{g}}\right.
$$

In the formula, GR is the theoretical real-time calculated generating capacity of inclined plane; GT is the theoretical calculated generating capacity of inclined plane (not considering temperature element); TR is the real-time temperature of the surface of module; )COg is the temperature coefficient of the module. According to the calculation principle above, collect the radiation data, generating capacity of inverter outlet, working temperature of modules and other parameters of several representative moments in the power station to calculate; the real-time generating efficiency of direct current components of PV power stations can be gained (Table 2).

Table 2: Real-time generating efficiency of direct current components of PV power stations

\begin{tabular}{|c|c|c|c|c|c|}
\hline No. & Time & $\begin{array}{c}\text { Real-time } \\
\text { radiation } \\
\text { /W } \cdot \mathrm{m}-3\end{array}$ & $\begin{array}{c}\text { Generating } \\
\text { capacity of } \\
\text { inverter outlet } \\
/ \text { MWh }\end{array}$ & $\begin{array}{c}\text { Real } \\
\text { temperature } \\
/{ }^{\circ} \mathrm{C}\end{array}$ & $\begin{array}{c}\text { Efficiency } \\
\text { after inversion } \\
/ \%\end{array}$ \\
\hline 1 & $2016-5-3012: 30$ & 1207.99 & 844.68 & 55 & 84.85 \\
\hline 2 & $2016-5-89: 10$ & 528.81 & 376.04 & 35 & 82.27 \\
\hline 3 & $2016-7-1814: 30$ & 351.94 & 281.23 & 25 & 82.97 \\
\hline 4 & $2016-10-2512: 49$ & 31.35 & 26.82 & 5 & 82.05 \\
\hline
\end{tabular}

The total efficiency of power station should also consider the loss of alternating current; it is necessary to take the real-time generating capacity (house supply has been taken out) of 35kV high-pressure side pass of the corresponding power stations in power stations to calculate and to gain real-time generating efficiency, which can be seen in Table 3.

Table 3 Real-time generating efficiency of PV power station of different representative moments

\begin{tabular}{|c|c|c|c|c|c|}
\hline No. & Time & $\begin{array}{c}\text { Real-time } \\
\text { radiation } \\
\text { /W } \cdot \mathrm{m}-3\end{array}$ & $\begin{array}{c}\text { Direct } \\
\text { current } \\
\text { efficiency /\% }\end{array}$ & $\begin{array}{c}\text { Alternating } \\
\text { current } \\
\text { efficiency / \% }\end{array}$ & $\begin{array}{c}\text { Power } \\
\text { station } \\
\text { efficiency /\% }\end{array}$ \\
\hline 1 & 2016-5-3012: 30 & 1207.99 & 844.68 & 55 & 84.85 \\
\hline 2 & $2016-5-89: 10$ & 528.81 & 376.04 & 35 & 82.27 \\
\hline 3 & $2016-7-1814: 30$ & 351.94 & 281.23 & 25 & 82.97 \\
\hline 4 & $2016-10-2512: 49$ & 31.35 & 26.82 & 5 & 82.05 \\
\hline
\end{tabular}




\section{Analysis of power loss}

The shadow covering makes the voltage and current produced by different batteries on the same module different; as for some batteries, they consume power as load, which may create hot spot effect and cause unrecoverable loss on module. The model sketch map of module containing $m \times n$ batteries can be seen in Figure 1. Although every $n$ batteries have antiparallel bypass diode aside, a low-impedance path with energy dissipation can solve the problem above; but experiment shows that under different block models, the output power of PV module may have obvious differences.

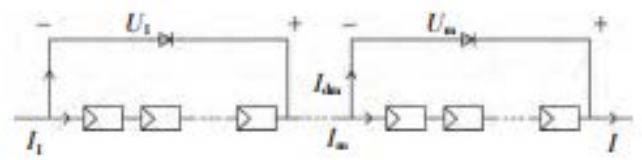

Figure 1: Sketch of module model

Suppose there are 36 batterisecommected in series to form PV module which can be seen in Figure 3 , the vertical block takes module's short side as initial system of reference; as long as the row of batteries at the bottom are blocked, the output power of the whole block is 0 ; the horizontal block takes module's long side as initial system of reference, and the blocked side part cannot generate electricity, but the unblocked batteries can stille work.

\begin{tabular}{|c|c|c|c|c|c|c|c|c|}
\hline 1 & 2 & 3 & 4 & 5 & 6 & 7 & 8 & 9 \\
\hline 10 & 11 & 12 & 13 & 14 & 15 & 16 & 17 & 18 \\
\hline 19 & 20 & 21 & 22 & 23 & 24 & 25 & 26 & 27 \\
\hline 28 & 29 & 30 & 31 & 32 & 33 & 34 & 35 & 36 \\
\hline
\end{tabular}

Figure 2: Sketch of module shadow blocking patterns

Module mismatch. Limited by the manufacturing techniques, there is certain deviation in the optimum operating voltage and current among different modules; there will be current loss at the time of module cascade and voltage loss at the time of parallel connection. When the voltage and the current of modules in the same string have large dispersion, the output power of all the modules of this string will be narrowed at the minimum value, which causes power loss of most modules in the string. The expression is:

$$
\Delta P(m, n)=\sum_{i=1}^{n} \sum_{j=1}^{m}\left(P_{i j}-P_{i 0}\right)
$$

\section{Optimization of system efficiency}

In the PV power generation system, both the energy transmission process and the energy conversion process have certain power loss; although the influencing factors are various, in the engineering design, it is possible to optimize key chains from different agnles, so as to decrease the power loss and to advance the whole performance of system. At the time of site selection of PV power station, it is necessary to avoid the areas with heavy pollution or too many barriers around; it is also necessary to adjust the fore-and -aft clearance of PV array reasonably; according to principle, during 9:00 15:00 on winter solstice, the PV array should not be blocked; if there is a small amount of shadow to block, it is necessary to consider module's install mode, to avoid large loss of output power. Module mismatch. At the stage of electric test, it is necessary to screen the modules with power positive deviation, to make exquisite sub-file according to power, current, and voltage, and to elevate the consistency of parameters of module performance; at the time of cascade, it is necessary to choose modules with the same working current and at the time of parallel connection, it is necessary to choose modules with the same working voltage. 


\section{Summary}

This paper divide energy industry into oil and gas exploration industry, coal mining and washing industry and power industry; at the time of designing this power station, the original estimation method considers to divide the generating efficiency into three parts: PV array efficiency, inverter efficiency, alternating grid-connected efficiency.

(1) PV array efficiency $\eta$ : consider the loss of PV array in energy conversion and transmission. Including: module matching loss, blocking loss of surface dust, unavaible solar radiation loss, influence on temperature and loss on DC transmission line, and so on. Take $\eta 1=84 \%$;

(2) Inverter's conversion efficiency $\eta_{2}$ : consider the loss in inverter conversion, loss of significance of maximum power point tracing (MPPT) , and so on. Take $\eta_{2}=96 \%$;

(3) Alternating current grid-connected efficiency $\eta_{3}$ : consider the transmission efficiency from inverter to grid system, among which the main parts are the efficiency of boosting transformer and the loss on the line connecting alternating current. Take $\eta_{3}=95 \%$.

The total efficiency of the system adopts the product of efficiency of different parts above, which is $\eta=\eta_{1} \times \eta_{2} \times \eta_{3}=84 \% \times 96 \% \times 95 \%=77 \%$.

The analysis above shows that the real generating efficiency of power station is higher than real design efficiency. The real generating efficiency of direct current part in the power station $\left(\eta_{1} x \eta_{2}\right)$ is higher than the design efficiency value $80.64 \%$, with the main reasons as following:

(1) The location of power station has efficient vegetation, clean air; the blocking loss of dust on PV module surface is lower than expectation;

(2) The location of power station has small daily temperature range and the PV module is not influenced by the temperature very much.

According to the real situation of power station, some detail design should be improved to elevate the overall efficiency of power station. The location of power station is typical karst landform, with complicated topography. The real use of direct current cable is higher than the design value; during the later period of power station construction, it is necessary to arrange combiner box reasonbaly according to the real landform so as to reduce the using quantity of DC cable and to decrease the initial investment of power station, and to elevate the generating efficiency of power station and the benefit of power station. At the time of designing module bracket, the original appearance of the position is not interfered. In the design of local fixed bracket, there is certain angle between the east-west direction and the horizontal plane, which may decrease the contribution of module. The first installment of this power station is $10 \mathrm{MWp}$; in the design stage, $35 \mathrm{kV}$ generator transformer adopts 12.5 MVA capacity transformer. Through the analysis on the actual capacity of power station, the actual capacity of power station is slightly higher than 10 MVA. If the design stage has the historical data of solar radiation, it is possible to make perfect forecast on the actual capacity of power station, to choose the generator transformer with capacity matching power staation, and to decrease the no-load loss on the alternating current part of PV power station.

\section{References}

[1] Gong Maofa, Wang Wanle, Li Zhi, Fan Shuxian, Feng Jie. Design of PV Array Simulator Based on MSP430 and Kingview [J]. Electrical Measurement \& Instrumentation,2017,06:49-54.

[2] Wu Ruiyun. Study and Design on PV Grid-connected Remote Monitoring System [J]. Construction \& Design for Project,2017,06:53-54.

[3] Wu Yongchang. Distributed PV Power Station Scheme [J]. Science and Technology Innovation and Application, 2017,12:4-6.

[4] Yao Jinlei. PV Power Generation Active Automatic Control Technology Feasibility and Key Techology [J]. Communication World, 2017,08:142-143.

[5] Jiang Zhenwei, Gai Wenqi. Technology Innovation, Industrial Innovation System and Value Creation --- Based on Chinese PV Industry View [J]. Central South University Journal (Social Science Edition), 2017,02:111-119+140. 
[6] Zhang Jie, Lei Dian. Monitoring System Design Based on DDS [J]. Industrial Control Computer, 2017,04:50-52.

[7] Wei Laiwei. Exploration on Solar PV Power Technology[J]. Low Carbon World,2017,10:48-49

[8] Cheng $\mathrm{Xu}$, Zhou Hai, Cui Fang, Ding Jie. Preestimate and Forecast System Design on High-capacity Grid-connected PV Power [J]. Hydropower Automation and Dam Monitoring, 2011,05:1-4+20. 